\title{
(2) OPEN ACCESS \\ Bilateral myopic strabismus fixus with fat prolapse treated by silicone band loop myopexy and excision of fat
}

\author{
Sakshi Lalwani 두, Ramesh Kekunnaya
}

Paediatric Ophthalmology, Strabismus and Neuroophthalmology, Child Sight Institute, Jasti V Raamanamma Children's Eye Care Center,LV Prasad Eye Institute, Hyderabad, Telangana, India

\section{Correspondence to} Dr Ramesh Kekunnaya; drrk123@gmail.com

Accepted 13 February 2021

(D) Check for updates

(C) BMJ Publishing Group Limited 2021. Re-use permitted under CC BY-NC. No commercial re-use. See rights and permissions. Published by BMJ.

To cite: Lalwani $S$, Kekunnaya R. BMJ Case Rep 2021;14:e238364. doi:10.1136/bcr-2020238364

\section{DESCRIPTION}

A 60-year-old man presented to our outpatient clinic with chief complaints of progressive inward deviation of both eyes and presence of a yellowish mass in both eyes for 2 years. On examination, the best-corrected visual acuity in the right eye (RE) was perception of light with accurate projection of rays and 20/126 in the left eye (LE). On ocular motility evaluation, there was limitation of abduction and elevation of -4 (figure 1A). The modified Krimsky test showed a large esotropia of about 110 prism diopters (PD) and 14 PD hypotropia in both eyes. A subconjunctival, yellow, soft, avascular, non-pulsatile, mobile mass was noticed supero-temporally in both eyes (figure $1 \mathrm{~B}$ ). While the palpebral part of the lacrimal gland was not visible, the orbital part could not be palpated. Examination of the anterior segment showed surgical aphakia in the RE and nuclear cataract in the LE. Fundus examination showed severe myopic tessellations in both eyes with normal optic discs, and there was a chorio-retinal atrophic patch involving the macula, suggestive of myopic maculopathy in the RE. The axial length was 34.21 and $34.41 \mathrm{~mm}$ in the RE and LE, respectively. CT scan of the orbit showed nasal shift of the superior rectus (SR) and inferiorisation of the lateral rectus (LR) with extraconal fat prolapse bilaterally (figure 1C).

A diagnosis of myopic strabismus fixus (MSF) with orbital fat prolapse was made. The patient underwent an LR and SR muscle union using a silicone band and a medial rectus muscle recession with orbital fat excision bilaterally. Intraoperatively, the forced duction test was positive for the medial rectus muscle. The silicone loop myopexy and orbital fat excision were both done in a single sitting. There was minimal inflammation

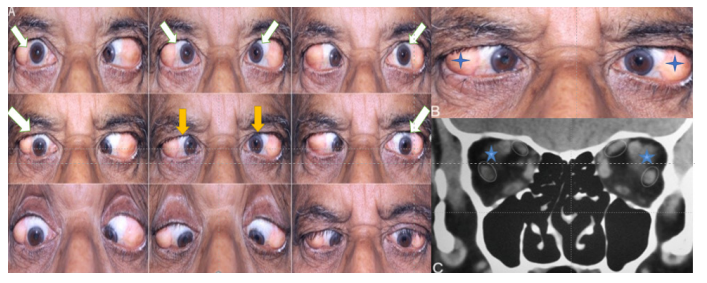

Figure 1 (A) Nine gaze clinical photographs depicting esotropia with hypotropia in primary gaze (yellow arrows) with marked limitation of abduction and elevation (white arrows). (B) Clinical photograph of severe orbital fat prolapse in the supero-temporal quadrant of the globe (blue asterisk). (C) Coronal cut of CT image depicting orbital fat prolapse in the supero-temporal quadrant of the orbit (blue star) with nasalisation of superior rectus and inferiorisation of lateral rectus (encircled). in the immediate postoperative period, for which we prescribed topical anti-inflammatory agents. The surgical procedure led to a desirable outcome; the patient had a residual esotropia of 25-30 PD and an improvement in the abduction ( -4 limitation to -1 , on a scale of $0-4$ ), in the immediate postoperative period with complete resolution of fat prolapse. The patient was however lost to follow-up.

Horizontal strabismus associated with myopia can manifest in various forms, that is, infantile, intermittent, constant, sensory and occasionally even with a small vertical component. However, MSF can manifest in two forms: esotropia-hypotropia complex and exotropia-hypotropia complex. ${ }^{1}$

This patient exhibited an esotropia-hypotropia complex form of MSF. In such patients, there is a supero-temporal dislocation of the posterior portion of the elongated globe from the muscle cone due to increased axial length. This causes an inferior displacement of the LR leading to abduction limitation and nasal displacement of the SR, thereby causing an elevation limitation. ${ }^{2}$

This could be appreciated on coronal cuts of a CT scan of the orbit (figure 1C). However, the best modality for soft tissue and extraocular muscle path delineation is MRI. The socio-economic status of the patient precluded getting an MRI done. While the inferior displacement of LR leads to weakening of abducting force and converts it to a depressor, nasalisation of the SR weakens its elevating force and converts it to an adductor, thereby leading to esotropia and hypotropia. The majority of these patients tend to have a myopia of $>15 \mathrm{D}$ and axial length of $>31 \mathrm{~mm}^{2}$

The surgical procedure to restore the dislocated globe back into muscle cone by uniting muscle bellies of SR and LR is very effective for MSF. ${ }^{3}$ Bilateral silicone band loop myopexy of LR-SR with or without bilateral medial rectus muscle recession is a good procedure to improve the alignment and extra-ocular motility. The intraoperative and postoperative complications like globe perforation, splitting of muscle, suture-related complications and anterior segment ischaemia are less seen in loop myopexy as compared with suture myopexy. ${ }^{4}$

Subconjunctival orbital fat prolapse is the prolapse of intraconal fat through a weakness in the tenon's capsule. ${ }^{5}$ Management of orbital fat prolapse includes either excision of the fat or conjunctival suturing of the fat to the sclera. ${ }^{6}$

In this case, both procedures were approached via a forniceal conjunctival incision made between SR and LR. The LR was then exposed and hooked. The 
prolapsed fat was approached through the same incision. The septa over the prolapsed fat was dissected to expose the fat globules. The base of the globules was clamped with an artery forceps and the fat was excised using a bipolar radiofrequency cautery. The visible fat was debulked and no attempt was made to pull out residual extraconal fat. In order to induce fibrosis and prevent further fat prolapse, the base of the debulked fat pad was cauterised using a bipolar cautery. Care was taken to avoid injuring the palpebral lobe of the lacrimal gland and the insertion of the LR muscle while dissection. The SR was then exposed and hooked. Using a crescent knife, a scleral tunnel was made $14 \mathrm{~mm}$ behind the limbus, midway between the SR and the LR muscles. A number 240 silicone band was passed around the SR, passed through the scleral tunnel and then around the LR, thereby approximating the SR and LR muscles.

This case was unique in terms of bilaterality, displacements of SR and LR muscles and fat prolapse. Although MSF has been widely

\section{Learning points}

Modified scleral fixated silicone band loop myopexy with or without medial rectus (MR) recession is a safe and effective procedure in the management of esotropia-hypotropia in myopic strabismus fixus, since this procedure normalises the vector forces of the lateral rectus and superior rectus.

- Intraoperatively, if there is a tight MR in addition to a large esotropia in primary position, this procedure can be combined with bi-MR recession.

- Muscle and fat prolapse can occur simultaneously which is amenable to surgery with good outcome. reported, fat prolapse in MSF is unknown or has not been published to the best of our knowledge.

Acknowledgements RK is a consultant in Paediatric Ophthalmology, Child Sight Institute Kallam Anji Reddy Campus, LV Prasad Eye Institute, Hyderabad, Telangana, India.

Contributors RK and SL wrote the paper and edited the images. RK managed the patient and acquired the images. SL conceptualised the case report images. RK is the overall guarantor of the paper.

Funding Hyderabad Eye Research Foundation

Competing interests None declared.

Patient consent for publication Obtained.

Provenance and peer review Not commissioned; externally peer reviewed.

Open access This is an open access article distributed in accordance with the Creative Commons Attribution Non Commercial (CC BY-NC 4.0) license, which permits others to distribute, remix, adapt, build upon this work non-commercially, and license their derivative works on different terms, provided the original work is properly cited and the use is non-commercial. See: http://creativecommons.org/ licenses/by-nc/4.0/.

\section{ORCID iD}

Sakshi Lalwani http://orcid.org/0000-0003-4530-1707

\section{REFERENCES}

1 Al Oum M, Donati S, Cerri L, et al. Ocular alignment and refraction in preterm children at 1 and 6 years old. Clin Ophthalmol 2014;8:1263.

2 Kekunnaya R, Chandrasekharan A, Sachdeva V. Management of strabismus in myopes. Middle East Afr J Ophthalmol 2015;22:298-306.

3 Yamaguchi M, Yokoyama T, Shiraki K. Surgical procedure for correcting globe dislocation in highly myopic strabismus. Am J Ophthalmol 2010;149:341-6.

4 Shenoy BH, Sachdeva V, Kekunnaya R. Silicone band loop myopexy in the treatment of myopic strabismus fixus: surgical outcome of a novel modification. $\mathrm{Br} J$ Ophthalmol 2015;99:36-40

5 Kim YD, Goldberg RA. Orbital fat prolapse and dermolipoma: two distinct entities. Korean J Ophthalmol 1994;8:42-3.

6 Nakamura N, Akiyama K, Shigeyasu C, et al. Surgical repair of orbital fat prolapse by conjunctival fixation to the sclera. Clin Ophthalmol 2015;9:9.

Copyright 2021 BMJ Publishing Group. All rights reserved. For permission to reuse any of this content visit

https://www.bmj.com/company/products-services/rights-and-licensing/permissions/

BMJ Case Report Fellows may re-use this article for personal use and teaching without any further permission.

Become a Fellow of BMJ Case Reports today and you can:

- Submit as many cases as you like

- Enjoy fast sympathetic peer review and rapid publication of accepted articles

- Access all the published articles

Re-use any of the published material for personal use and teaching without further permission

Customer Service

If you have any further queries about your subscription, please contact our customer services team on +44 (0) 2071111105 or via email at support@bmj.com.

Visit casereports.bmj.com for more articles like this and to become a Fellow 